\title{
Income Generation of Tribal Farmers of Adilabad and their Relationship with Profile Characteristics
}

\author{
L. Mahesh*, V. Sudharani, K.B. Suneetha Devi and M. Jagan Mohan Reddy \\ Department of Agricultural Extension, Prof. Jayashankar Telangana State Agricultural \\ University, College of Agriculture, Rajendranagar, Hyderabad - 500030, India
}

*Corresponding author

\section{A B S T R A C T}

\section{Key words \\ Income generation, Profile \\ characteristics and tribal farmers \\ Article Info \\ Accepted: \\ 15 October 2018 \\ Available Online: \\ 10 November 2018}

The present study was conducted in Adilabad district of Telangana to study the profile and employment generation of tribal farmers. Total 120 respondents were randomly selected for the study and interviewed. Most of the $(44.10 \%)$ respondents belonged to medium category followed by low $(39.20 \%)$ and high $(16.70 \%)$ income generation. The results of the investigation it was found that farm size, training received, credit orientation, achievement motivation, social support, extension contact and mass media exposure had a positive and significant correlation with the income generation. Whereas, age, farming experience and ethnocentrism had a negatively significant correlation with income generation. The variables education, risk orientation and religious belief had no significant effect on income generation.

\section{Introduction}

Economic and social empowerment and educational up-liftment of socially disadvantaged groups and marginalized sections of society is necessary for achieving faster and more inclusive development. There are twenty countries in the world with substantial tribal population. India has the largest tribal population in the world. The tribal population of the country, as per 2011 census, is 10.43 crore, constituting 8.6 per cent of the total population. Tribal groups are very heterogeneous. India's tribals are a diverse and heterogeneous group. Some are still in the food gathering stage, others practice shifting cultivation, yet others may be pursuing primitive forms of agriculture.

Telangana state is very rich in the variety of cultures that represent all stages of human progress. We have the Chenchus, as primitive as those who lived in Stone Age and at the same time tribes such as Gonds who are in no way inferior to their neighbours. Andhs and Bhils are backward and yet assimilated enough to be hardly distinguished. From the Gond settled cultivators to the Koyas and Konda Reddis who are still found inclined to indulge in shifting cultivation, we see the Chenchus who would not care to produce anything and prefer to live on the roots, tubers 
and other forest produce. The sustainable livelihood approach enables development departments to improve the design and implementation of poverty alleviation efforts in tribal areas. It helps to analyze opportunities and constraints of the tribal poor, builds better understanding of multiple perspectives, identifies what options have better potential to reduce poverty and what enabling conditions, policies and incentives are needed for the poor to increase the range of better livelihood options.

Hence, "a study on sustainable livelihoods of tribal farmers of Adilabad district in Telangana state" would enable development agencies to design appropriate and suitable programmes to create and provide sustainable livelihood options to tribal farmers.

\section{Materials and Methods}

For this study, ex-post facto research design was adopted. According to Kerlinger (1973), ex-post facto research is a systematic empirical enquiry, in which the scientists do not have direct control on influencing (independent) variables because their manifestations have already occurred. Telangana was purposively selected for the study as the researcher is from this state. Adilabad district of Telangana was purposively selected for the study as Adilabad district has a population of about 4,95,794 scheduled tribes and this district is ranked $3^{\text {rd }}$ in scheduled tribes areas, after Khammam and Warangal in the state. Out of 53 mandals 35 mandals were having more tribal population. Out of 35 mandals two mandals were selected randomly. Three villages from each of the two mandals were selected by following simple random sampling method, thus making total of six villages. From each of the selected village twenty (20) respondents were selected by following random sampling procedure, thus making a total of 120 respondents.
Income generation operationalized as the income in rupees generated by the respondent from the livestock, crop enterprises, Non Timber Forest Products and through other Government programmes and schemes.

Scoring and categorization: scoring and categorization

A schedule was developed for the variable and respondents were categorised into three categories based on exclusive class interval method as low, medium and high level of income generation. A score of 1 was assigned to every rupee of income generated. The results were expressed in frequency and percentages. The obtained scores varied from 30000 to 120000 .

\section{Results and Discussion}

It was evident from table 1 that 44.10 per cent of respondents belong to medium category followed by low (39.20\%) and high (16.70\%) income generation respectively.

The medium to low trend of income generation may be attributed to the fact that the tribal farmers were unable to get minimum price for their crop produce and their non timber forest produce collection.

High religious belief and ethnocentrism might have prevented them to go for better or improved livelihood options or income generating activities. The administration should take necessary measures to address the problem related to their income generation through an integrated approach, involving ITDA, Department of agriculture and line departments, banks, NGOs and the PRIs. Imparting skill development training, adult education and support for their sustainable livelihood may help improving their income generation. These findings are in contrary with the results of Krishnaprasad (2005) and in accordance with Kiran (2011). 
Relationship between selected independent variables and income generation of tribal farmers on sustainable livelihoods

In order to study the relationship between the income generation of tribal farmers from sustainable livelihoods and their profile characteristics, the correlation co-efficient (r) values were computed and findings are furnished here under.

The relationship between the income generation of tribal farmers from sustainable livelihoods and their profile characteristics was tested by relevant null and empirical hypotheses.

\section{Null hypothesis}

There will be no significant relationship between profile characteristics of the respondents with income generation of tribal farmers from sustainable livelihoods and both of these are independent.

\section{Empirical hypothesis}

There will be significant relationship between profile characteristics of the respondents and income generation to tribal farmers from sustainable livelihoods and both of these are dependent.

It is revealed from the table 2 that, calculated ' $r$ ' values between training received and the income generation were greater than table ' $r$ ' value at 0.05 level of probability, whereas, the calculated ' $r$ ' value of the variables age, farm size, farming experience, credit orientation, achievement motivation, social support, extension contact, mass media exposure and ethnocentrism were greater than table ' $r$ ' value at 0.01 level of probability. Hence, null hypothesis was rejected and empirical hypothesis was accepted. Therefore, it can be concluded that there was a positive and significant relationship between income generation by tribal farmers from sustainable livelihoods and the variables farm size, training received, credit orientation, achievement motivation, social support, extension contact, mass media exposure.

On the other hand calculated ' $r$ ' values between age, farming experience and ethnocentrism and the income generation were less than table ' $r$ ' value. Hence, null hypothesis was accepted. Therefore, it can be concluded that there was no significant relationship between the between income generation of tribal farmers on sustainable livelihoods and education, risk orientation and religious.

\section{Age Vs income generation}

From the findings it was evident that a negative and significant correlation exists between age and income generation. This may be due to the fact that most of the respondents were of middle to young age and were more interested in government wage employment works under MGNREGA and other schemes as compared to working in their fields due to the nature of work, convenience, easy earning, secured income.

The development agencies should create awareness and interest about diversified income generating activities among the tribal community to increase their income generation capacity. These findings are in accordance with the results of Chandrasekher (1995).

\section{Education Vs income generation}

It was evident from the table 2 that education had no significant effect on the dependent variable income generation. These findings are in accordance with the results of Prajapati et al., (2014) and Chandrasekher (1995) 


\section{Farm size Vs income generation}

From the findings it was apparent that a positive and significant correlation exists between farm size and income generation. As discussed in case of employment generation, income generation also might be increased with increase in the farm size due to the possibility of additional components, resulting in increased income. The development agencies should come up with suitable Integrated Farming System approach for increase in the farming intensity and income generation. These findings are in accordance with the results of Chandrasekher (1995).

\section{Farming experience Vs income generation}

The variable farming experience had negative and significant correlation with income generation. The reason behind the negative trend may be due to the fact that the middle aged and young tribal farmers were more involved in relatively new technologies as compared to their older counterparts, who were still engaged in the old and traditional agricultural practices. The government should take initiatives to identify the innovative ones among the group for diffusion of the new and suitable practices in the study area for better income generation among the tribal farmers.

\section{Training received Vs income generation}

Similar to the previous dependent variable employment generation, this variable training received showed positive and significant correlation with income generation. As with higher level of knowledge and skills through training, correspondingly there would be enough chances for improvement in income generation too. Therefore target groups should be identified and imparted technical as well as entrepreneurial skills to enhance their income generation capacity.

\section{Risk orientation Vs income generation}

Findings of the investigation showed a nonsignificant relation between risk orientation and income generation, which means risk orientation had no significant effect on income generation. Probable reason for this might be that the tribal farmers believe in fate philosophy, they may not take risk adopting new technologies irrespective of its income generation potential.

\section{Religious belief Vs income generation}

Religious belief had negative and nonsignificant correlation with income generation. Which means income generation was not affected by the level of religious belief of the tribal farmers.

\section{Credit orientation Vs income generation}

Credit orientation showed positive and significant correlation with income generation means higher the credit orientation, higher will be the income generation. The reason for such a positive relation might be that with better credit orientation the tribal farmers could avail timely credit from genuine sources, which can eliminate the middleman or money lender menace, resulting in better income generation. Subsequently the tribal farmers can get timely inputs for their livelihood practices with reduced interest rates as compared to money lender. Thus, with the saved capital, they could add more components and enterprises in their livelihood, which will automatically improve their income generation capacity. Hence, the authorities concerned should look forward for making the credit mechanism more transparent and simple by bridging the existing gap in the banking system and formulate steps for uncomplicated repayment system. 
Achievement motivation Vs income generation

Achievement motivation had a positive and significant correlation with income generation, means if the person is motivated to achieve will have better income generation. It was observed that although the respondents had low achievement motivation, when it comes to certain livelihood activities of their taste like upaadi hami, short duration crops, beedi leaf collection, seasonal NTFP collection, which involves less investment and immediate income, they showed relatively high achievement motivation. So, if certain livelihood measures of their acceptance are identified and promoted, their overall achievement motivation could be improved, ultimately resulting in better income generation. These findings are in accordance with the results of Dhanasree et al., (2014).

Table.1a

\begin{tabular}{|c|c|c|}
\hline SL. NO. & Category & Class interval \\
\hline $\mathbf{1 .}$ & Low income generation & Rs $30000-60000$ \\
\hline $\mathbf{2 .}$ & Medium income generation & Rs $60000-90000$ \\
\hline 3. & High income generation & Rs $90000-120000$ \\
\hline
\end{tabular}

Table.1b Distribution of the farmers according to their income generation

$(n=120)$

\begin{tabular}{|c|l|c|c|}
\hline Sl. No. & Category & Frequency & Percentage \\
\hline $\mathbf{1}$ & Low (Rs 30000-60000) & 47 & 39.20 \\
\hline $\mathbf{2}$ & Medium (Rs 60000-90000) & 53 & 44.10 \\
\hline $\mathbf{3}$ & High (Rs 90000-120000) & 20 & 16.70 \\
\hline
\end{tabular}

Table.2 Relationship between independent variables and income generation by tribal farmers from sustainable livelihoods

\begin{tabular}{|l|l|l|}
\hline Sl. No. & Characteristics & Correlation coefficient $(\mathrm{r})$ \\
\hline $\mathbf{1 .}$ & Age & $\mathbf{- 0 . 3 3 3}$ \\
\hline $\mathbf{2 .}$ & Education & $\mathbf{- 0 . 0 2 0}$ \\
\hline $\mathbf{3 .}$ & Farm size & $\mathbf{0 . 4 9 9}^{* *}$ \\
\hline $\mathbf{4 .}$ & Farming experience & $\mathbf{- 0 . 3 3 6}^{* *}$ \\
\hline $\mathbf{5 .}$ & Training received & $\mathbf{0 . 2 2 8}^{*}$ \\
\hline $\mathbf{6 .}$ & Risk orientation & $\mathbf{- 0 . 0 3 1}^{*}$ \\
\hline $\mathbf{7 .}$ & Religious belief & $\mathbf{- 0 . 1 1 5}^{* *}$ \\
\hline $\mathbf{8 .}$ & Credit orientation & $\mathbf{0 . 2 3 5}^{* *}$ \\
\hline $\mathbf{9 .}$ & Achievement motivation & $\mathbf{0 . 6 5 9}^{* *}$ \\
\hline $\mathbf{1 0 .}$ & Social support & $\mathbf{0 . 3 6 3}^{* *}$ \\
\hline $\mathbf{1 1}$ & Extension contact & $\mathbf{0 . 2 8}^{* *}$ \\
\hline $\mathbf{1 2}$. & Mass media exposure & $\mathbf{0 . 4 4 9}^{* *}$ \\
\hline $\mathbf{1 3}$. & Ethnocentrism & $\mathbf{- 0 . 2 4 4}^{* *}$ \\
\hline
\end{tabular}

* Significant at 0.05 level of probability 


\section{Social support Vs income generation}

Social support had positive and significant correlation with income generation. It was obvious that with better support from different government agencies, NGO's and friends, the respondents could improve their chances of employment generation which may lead to the high income generation. Group activities like SHGs, Cooperative Societies, Commodity Interest Groups, Grower Groups etc., should be formed to encourage supportive climate among the tribal community as well as with the agencies involved in tribal welfare.

\section{Extension contact Vs income generation}

Extension contact had positive and significant correlation with income generation. It may be attributed to the fact that with the increase in contact with extension activities and extension personnel, there may be more chances of getting better quality seeds or inputs from govt officials on subsidy basis and by that they can reduce cost of livelihood practices and can result in better income generation. As mentioned earlier, the government should try to ensure sufficient staff strength in the agencies involved in extension in order to reach the unreached. These findings are in accordance with the results of Dhanasree et al., (2014) and Ratnakar(1990).

\section{Mass media exposure Vs income generation}

Mass media exposure had positive and significant correlation with income generation. This trend may be due to the fact that with sufficient exposure to mass media tools like, T.V, radio, kisan melas, ICT's, news paper and agricultural magazines, tribal people can know better about market prices and new income generation activities. To increase mass media exposure government should conduct more kisan melas, target based television shows and strengthening of ICT tools can also provide good platform for improved mass media exposure among the tribal farmers. Community radio can also be a good initiative for the study area, which can cater the need for information in local languages. These findings are in accordance with the results of Chandrasekher (1995).

\section{Ethnocentrism Vs income generation}

There was a negative and significant correlation between ethnocentrism and the dependent variable, income generation. This trend may be owing to the fact that the tribal have more respect for their culture and values and may feel reluctant to allow others to enter into their community and system, which may result in closing of opportunities for better income generating. Exposure visits, group discussions and rapport building activities should be taken up among the tribal farmers, to over come the problem. These findings are in accordance with the results of Prajapati et al., (2014).

\section{References}

Chandrasekher, S. 1995. A study on the effectiveness of selected agricultural programmes of ITDA on tribal farmers in Adilabad district of Andhra Pradesh. M.Sc. (Ag.) Thesis. Andhra Pradesh Agricultural University, Rajendranagar, Hyderabad.

Dhanasree, K., Vijayabhinandana, B and Pradeepkumar, P.B. 2014. Socioeconomic empowerment of tribal women in high altitude and tribal zone of Andhra Pradesh. International Journal of Innovative Research in Science, Engineering and Technology. 3(2): 9360-9368. 
Kerlinger, F.N. 1973. Foundations of behavioral research. Holt, Rinehart and Winston. New York.

Kiran, S. 2011. A critical study on livelihoods of tribal farmers in Andhra Pradesh. Ph. $D$ Thesis. The School of Agricultural Sciences, Yashwantrao Chavan Maharashtra Open University, Nashik, Maharashtra, India.

Krishnaprasad, T. 2005. A study on rural poverty and sustainable livelihood in agrarian sector of Andhra Pradesh. Ph. $D$ Thesis. Acharya N G Ranga
Agricultural University, Hyderabad, India.

Prajapati, M., Solanki, K.D., Patel R And Dhandhukia, R. 2014. Measurement of the existing sustainable livelihood of the tribal and non-tribal farmers. Advance Research In Agriculture And Veterinary Science. Vol. (1) 2: 83-87

Ratnakar, R. 1990. Study on impact of ITDA on the tribal farmers of Khammam district of Andhra Pradesh. Ph. D Thesis. Andhra Pradesh Agricultural University, Hyderabad, India.

\section{How to cite this article:}

Mahesh, L., V. Sudharani, K.B. Suneetha Devi and Jagan Mohan Reddy, M. 2018. Income Generation of Tribal Farmers of Adilabad and their Relationship with Profile Characteristics. Int.J.Curr.Microbiol.App.Sci. 7(11): 2035-2041. doi: https://doi.org/10.20546/ijcmas.2018.711.231 